\title{
Testando as Implicações do Modelo Intertemporal da Conta-Corrente para o Brasil: 1947-2010*
}

\section{Testing the Implications of the Intertemporal Current Account Model for Brazil: 1947-2010}

Carlos Enrique Carrasco-Gutierrez** Lucio Hellery Holanda Oliveira* **

Resumo: De acordo com a abordagem intertemporal, uma das maneiras mais importantes para a descrição da dinâmica internacional de capitais é a contacorrente. Este artigo aplica para dados brasileiros a técnica econométrica desenvolvida por Campbell (1987) e Campbell e Shiller (1987) para testar o modelo intertemporal da conta-corrente para o período de 1947 até 2010. Comparam-se os resultados obtidos neste trabalho com outros apresentados para a economia brasileira de forma a estabelecer a robustez do modelo para diferentes períodos. Os resultados obtidos corroboram alguns fatos estilizados apresentados na literatura e mostram que nem todas as proposições básicas testáveis do modelo intertemporal da conta-corrente foram confirmadas. Contudo, uma análise menos formal sugere um elevado grau de mobilidade de capitais e fluxos significativos de capitais especulativos, pois a série de conta-corrente ótima mostrou-se menos volátil que a série observada no período.

Palavras-chave: Conta-corrente. Modelo intertemporal. Mobilidade de capitais. VAR.

Abstract: According to the intertemporal approach, one of the most important ways to describe the dynamics of international capital is the current account. This paper applies to Brazilian data econometric technique developed by Campbell (1987) and Campbell and Shiller (1987) to test the intertemporal current account model for the period 1947 to 2010. It compares the results obtained in this work with others presented to the Brazilian economy in order to establish the robustness of the model for different periods. The results confirm some stylized facts presented in the literature and show that not all basic propositions testable of the intertem-

\footnotetext{
* As opiniões expressas neste trabalho são exclusivamente do autor e não refletem, necessariamente, a visão do Banco Central do Brasil.

** Doutor em Economia e doutor em Engenharia Elétrica. Professor adjunto do Programa de Pós-Graduação em Economia da Universidade Católica de Brasilia (UCB). E-mail: carlosgutierrez@ucb.br

*** Mestre em Economia pela Universidade Católica de Brasília (UCB) e analista do Banco Central do Brasil. E-mail: lucio.holanda@bcb.gov.br
} 
poral current account model were confirmed. However, a less formal analysis suggests a high degree of capital mobility and significant inflows of speculative capital, because the optimal series of the current account was less volatile than the observed series in the period.

Keywords: Current account. Intertemporal model. Capital mobility. VAR.

JEL Classification: E27; F32; F41.

\section{Introdução}

O modelo inicial que trata a teoria intertemporal da conta-corrente foi desenvolvido por Sachs (1982) e posteriormente disseminado por Obstfeld e Rogoff (1996). Nesse modelo, emprega-se a hipótese de perfeita mobilidade de capitais sob a teoria da renda permanente, na qual os choques temporários na economia afetam a conta-corrente. Quando os choques são permanentes, entretanto, os agentes econômicos ajustam seus níveis de consumo e o efeito sobre a contacorrente deve ser relativamente pequeno.

Sob essa abordagem, a conta-corrente apresenta déficits sempre que há expectativas de aumento do produto líquido futuro, definido como o produto interno bruto (PIB), excluídos os investimentos e os gastos públicos. Intuitivamente, se os agentes econômicos de um país esperam um aumento do produto líquido futuro, eles contraem empréstimos no exterior para consumir hoje, antecipando o aumento da renda e gerando déficit na conta-corrente. De forma oposta, há superávit na conta-corrente quando se espera uma queda futura do produto líquido (OBSTFELD; ROGOFF, 1996).

A partir desse modelo, pode-se definir a conta-corrente ótima como sendo aquela consistente com o nível ótimo de movimentos de capitais que permite aos agentes econômicos suavizarem o consumo na presença de choques. A estimação da conta-corrente ótima e sua comparação com os dados observados para a conta-corrente no Brasil possibilitam testar se há mobilidade de capitais para o país. A comparação das volatilidades dessas duas séries pode, por exemplo, indicar a existência de fluxos de capitais especulativos.

Os resultados empíricos obtidos neste trabalho visam proporcionar uma contribuição para a literatura econômica brasileira em relação às implicações da dinâmica intertemporal da conta-corrente até um período mais recente, uma vez que as séries de dados empregadas no modelo compreendem um período de mudanças macroeconômicas importantes nos últimos anos, podendo-se destacar:

a) a implantação do Plano Real em 1994 e a estabilização da economia;

b) as incertezas políticas decorrentes de eleições presidenciais em 2002; 
c) um processo mais intenso de estímulo à "bancarização" e oferta de crédito a partir de 2003;

d) a crise financeira do mercado hipotecário americano iniciada em 2007; e

e) a crise da dívida pública da zona do euro, que vem se estendendo a diversos países da Europa desde 2010.

A principal contribuição deste trabalho é avaliar a robustez de modelo quando consideradas as importantes mudanças macroeconômicas no cenário nacional e internacional nos anos mais recentes. Foram avaliadas neste trabalho as quatro proposições do modelo intertemporal apresentadas originalmente por Sheffrin e Woo (1990) e Otto (1992):

a) se há estacionariedade na série da conta-corrente;

b) se a conta-corrente causa, no sentido de Granger, variações no produto líquido;

c) se há igualdade estatística entre as séries de conta-corrente ótima e real;

d) se existe uma relação próxima entre as séries ótima e real.

Os resultados obtidos sugerem que as proposições básicas testáveis do modelo intertemporal da conta-corrente foram confirmadas apenas parcialmente. Contudo, uma análise menos formal sugere um elevado grau de mobilidade de capitais e fluxos significativos de capitais especulativos, pois a série de contacorrente ótima mostrou-se menos volátil que a série real do período. Esses resultados estão de acordo com aqueles apresentados na literatura para a economia brasileira para outros períodos.

O artigo está estruturado em cinco seções: a primeira apresenta esta introdução; a segunda faz uma revisão da bibliografia que trata do assunto; a terceira trata da teoria formal subjacente aos testes; a quarta faz a descrição do método econométrico adotado na abordagem intertemporal da conta-corrente; a quinta apresenta a base de dados e as estimativas do modelo; a sexta traz a comparação dos resultados deste trabalho com os apresentados anteriormente na literatura; e, finalmente, a sétima conclui o artigo.

\section{Revisão Bibliográfica}

Este trabalho utiliza a abordagem empregada por Campbell (1987) desenvolvida originalmente para a poupança privada. Essa metodologia vem sendo empregada em diversos trabalhos para a análise dos movimentos da conta-corrente e foi adotada na literatura internacional para aplicar os testes econométricos em dados de diferentes economias. 
Sheffrin e Woo (1990) foram os primeiros a derivar um modelo similar ao de Campbell (1987) para a conta-corrente de uma economia aberta. Em seu trabalho, examinaram dados anuais do período de 1955 a 1985 de quatro países: Bélgica, Canadá, Dinamarca e Reino Unido, que foram selecionados por possuírem um nível relativamente baixo de controle de capitais. Basicamente, os autores efetuaram testes nos coeficientes do VAR estimado para verificar se a conta-corrente seria, conforme prevê a teoria do modelo intertemporal, igual a menos o valor presente esperado das variações do produto líduido. Os testes estatísticos realizados pelos autores mostraram que o modelo apresentou um desempenho razoável para a Bélgica e para o Canadá, porém foi rejeitado para a Dinamarca e para o Reino Unido. Otto (1992) realizou um trabalho pioneiro ao sistematizar os testes das implicações do modelo intertemporal sobre:

a) a estacionariedade da conta-corrente em nível;

b) a causalidade entre a conta-corrente e as variações do produto líquido;

c) a validade estatística das restrições do modelo; e

d) a possibilidade de existência de uma relação próxima entre a séries ótima e real, o que é verificado por meio da comparação da conta-corrente real com a estimada a partir do VAR.

O autor empregou dados trimestrais dos Estados Unidos e do Canadá, para os períodos de 1950 a 1988 e de 1950 a 1987, respectivamente. O modelo, avaliado a partir de suas implicações, foi rejeitado nos dois casos. Segundo Otto, a sua versão para a hipótese de suavização de consumo não foi capaz de fornecer uma explicação estatística adequada para justificar o comportamento dinâmico da conta-corrente daqueles dois países. Nos dois casos, as restrições formais decorrentes do modelo para a teoria do valor presente aplicado à conta-corrente foram fortemente rejeitadas. Ele destacou, contudo, que procedimentos menos formais, tais como a comparação da curva estimada com a curva real, sugerem que o modelo de suavização de consumo tem alguma capacidade de explicar o comportamento dinâmico da conta-corrente americana. Para o autor, a diferença entre os resultados obtidos para os Estados Unidos e para o Canadá não estava clara, já que este último se encaixaria melhor na premissa de uma pequena economia com taxa de juros real constante. Uma explicação alternativa seria que os resultados da conta-corrente do Canadá poderiam ser mais afetados por mudanças temporárias nos preços de recursos.

Gosh (1995) aplicou o modelo a países mais industrializados: Estados Unidos, Japão, Alemanha, Canadá e Reino Unido, propondo um modelo alternativo, baseado na comparação da variância das séries estimadas e real, e assim verificar a mobilidade de capitais nesses países - os trabalhos publicados até então 
se baseavam na avaliação da correlação entre poupança e investimento. O seu argumento se baseou no fato de que se o capital apresenta realmente mobilidade, então ele deve permitir a suavização do consumo frente a choques no produto líquido. $\mathrm{O}$ autor empregou dados trimestrais que se estenderam ao longo do período de 1960 a 1988 e concluiu que os fluxos de capitais observados eram excessivos, o que indicaria que eram movidos mais por forças especulativas do que por fundamentos econômicos. O modelo apresentou boa consistência em relação aos dados reais da conta-corrente desses países, com exceção do Canadá, em que os movimentos da conta-corrente foram muito maiores do que teria sido necessário para a suavização do consumo.

Sheffrin e Bergin (2000) desenvolveram um modelo intertemporal que introduziu taxas de juros variáveis e taxa de câmbio, considerando que essas variáveis adicionais são canais por meio dos quais choques externos podem influenciar a conta-corrente. Os autores analisaram os dados de três países: Canadá, Austrália e Reino Unido, empregando séreis trimestrais entre os anos de 1960 a 1996. O trabalho sugeriu que a inclusão das duas variáveis melhorou o ajuste do modelo intertemporal quando comparado a estudos realizados previamente, obtendo inclusive uma melhor estimativa da volatilidade da conta-corrente. Em alguns casos, os movimentos de taxas de juro e de câmbio poderiam explicar uma boa parcela dos movimentos de médio prazo da contacorrente que não haviam sido bem explicados a partir da teoria intertemporal mais simples empregada em testes anteriores. Isso se daria porque a contacorrente de uma pequena economia é afetada não somente por choques do produto interno ou dos gastos do governo, mas também por choques externos nas economias de países vizinhos relevantes. Tais choques externos poderiam afetar a economia doméstica via mudanças na taxa de juros internacional e na taxa de câmbio real do país, as quais têm papel fundamental na forma como a economia irá negociar ao longo do tempo com o resto do mundo, o que teria impacto na conta-corrente.

Gruber (2004) adicionou hábitos de consumo ao modelo intertemporal da conta-corrente. A estimação obtida sugere que os hábitos de consumo têm um importante papel na determinação da dinâmica da conta-corrente, uma vez que foi capaz de aproximar os resultados estimados de volatilidade da conta-corrente aos dados reais das economias da França, Alemanha, Itália, Japão, Holanda, Nova Zelândia, Espanha, Reino Unido e Estados Unidos. Nesse trabalho foram empregados dados trimestrais em períodos compreendidos entre os anos de 1957 e 2000. Segundo o autor, o trabalho ofereceu uma solução para o problema de excesso de volatilidade enfrentado pelo modelo intertemporal padrão da contacorrente, baseado na inclusão de hábitos de consumo. A medida do grau de formação de hábito foi realizada com base em estimação via método generalizado 
de momentos e o parâmetro estimado para a formação de hábito teve significância estatística para oito dos dez países estudados.

Nason e Rogers (2006) estudaram a importância de diferentes explicações para problemas de desempenho do modelo intertemporal básico de contacorrente, usando dados da economia canadense de 1963 a 1997. Foram avaliadas explicações tradicionais, tais como utilidade não separável no tempo, choques fiscais transitórios, choques de taxa de juros real internacional e imperfeita mobilidade de capitais internacional. O trabalho concluiu que, embora cada variável explorada tenha alguma importância para o modelo, nenhuma foi capaz de melhorar o ajuste das estimativas.

A abordagem intertemporal também foi utilizada para analisar movimentos da conta-corrente brasileira por Ghosh e Ostry (1995), Senna e Issler (2000) e Silva e Andrade (2006, 2007). Ghosh e Ostry (1995) testaram se, de fato, a contacorrente atua como uma poupança para permitir a suavização do consumo frente a choques no produto líquido. Eles estimaram a conta-corrente ótima e testaram econometricamente as proposições do modelo intertemporal para 45 países em desenvolvimento da África, Ásia, Oriente Médio e América Latina, para períodos compreendidos entre os anos de 1950 e 1991, obtendo a não rejeição do modelo em cerca de dois terços da amostra estudada, incluindo o Brasil, e sugerindo que a mobilidade de capitais seria bastante alta para esse grupo de países. Também foram os primeiros a aplicar os testes econométricos com dados da economia brasileira. Os autores também encontraram que tanto os movimentos no nível quanto na volatilidade da conta-corrente, tendo por base o modelo de suavização de consumo, são bem próximos aos movimentos reais. Eles não detectaram nenhuma tendência sistemática para que movimentos na conta-corrente real fossem menores do que os movimentos ótimos, o que seria o caso se houvesse barreiras efetivas e generalizadas aos movimentos internacionais de capitais. Para chegar a essas conclusões, empregaram tanto o uso de estatísticas formais, para testar as restrições do modelo, quanto a comparação dos gráficos das séries real e ótima.

Senna e Issler (2000) testaram as quatro proposições do modelo intertemporal da conta-corrente para a economia brasileira, com dados para o período de 1947 a 1997. Os resultados obtidos indicaram que nem todas as implicações do modelo se verificaram para os dados brasileiros, sendo a maior falha do modelo teórico a constatação da não existência da causalidade de Granger da contacorrente para o produto líquido, como o modelo previa. Segundo os autores, isso mostraria a inexistência de plena mobilidade de capitais, o que confirmaria as suspeitas levantadas a partir da análise histórica. Por outro lado, foram constatados elevado grau de mobilidade de capitais e significativos fluxos de capitais especulativos, pois a série de conta-corrente estimada mostrou-se menos volátil do que a série observada na economia brasileira. 
Silva e Andrade (2006) refizeram o exercício de se testar para o Brasil o modelo básico da abordagem intertemporal da conta-corrente para os anos de 1947 a 2003. A principal inovação do artigo constituiu-se na verificação do impacto sobre as transações correntes de choques com efeitos transitórios e permanentes no produto líquido. Além disso, foram construídos intervalos de confiança dos valores estimados da conta-corrente com o objetivo de refinar a análise gráfica do modelo. Os resultados obtidos nos testes econométricos tradicionais mostraram um fraco desempenho do modelo básico e, de forma contrária à prevista pelo modelo teórico, a análise impulso-resposta mostrou que os choques com efeitos permanentes no produto líquido afetaram significativamente a conta-corrente.

Silva e Andrade (2007) introduziram câmbio e juros no modelo básico da abordagem intertemporal da conta-corrente, uma vez que o modelo padrão assume as hipóteses restritivas de que todos os bens são comercializáveis e que a taxa de juros internacional é constante. Com a taxa de juros variável no tempo, os agentes podem substituir consumo presente por consumo futuro quando a taxa de juros estiver acima de seu nível normal. Esse efeito ocorre na medida em que tomar empréstimos se torna mais dispendioso. Em relação à taxa de câmbio, variações nessa variável acarretam substituições intertemporais. Foi seguido no artigo o modelo de Sheffrin e Bergin (2000) para avaliar a dinâmica das transações correntes e a mobilidade de capitais no Brasil. Os autores empregaram dados trimestrais de 1991:1 a 2004:1 e dados anuais de 1947 a 2003 da economia brasileira. Os resultados obtidos sugeriram que a introdução dessas variáveis no modelo intertemporal não foi suficiente para que se conseguisse explicar consistentemente as flutuações no saldo das transações correntes do Brasil.

\section{Modelo Teórico}

O modelo teórico no qual é baseado o presente trabalho consiste na abordagem intertemporal da conta-corrente, que tem como hipóteses básicas a existência de alta mobilidade de capitais entre países e a suavização do consumo por parte do agente representativo. Esse modelo foi apresentado nos trabalhos de Sachs (1982) e Obstfeld e Rogoff (1996) e sua principal característica é que a conta-corrente é usada pelo agente representativo de um país como um instrumento para a suavização do consumo, sobre perfeita mobilidade de capitais. Assim, os agentes econômicos poupam ou despoupam quando esperam variações futuras do produto líquido da economia.

O modelo consiste numa pequena economia aberta com um agente representativo que vive infinitos períodos e que pode emprestar e tomar emprestado recursos a uma taxa de juros fixa. Admite-se que a função utilidade do indivíduo 
seja separável no tempo, de modo que ao longo de toda sua vida a utilidade esperada do agente representativo, em valor presente, é dada por:

$$
U_{t}=E_{t}\left[\sum_{s=t}^{\infty} \beta^{s-t} u\left(c_{s}\right)\right]
$$

onde $E_{t}[$.$] é a esperança matemática condicional às informações disponíveis na$ data inicial $t, \beta \in(0,1)$ é o fator de desconto intertemporal que mede o grau de impaciência do indivíduo para consumir e $c_{t}$ é o consumo de um único bem.

O saldo da conta-corrente de um país no período $t$ é a variação do valor líquido dos seus ativos em relação ao resto do mundo. Quando há um superávit em conta-corrente é porque o país como um todo está emprestando recursos, e quando há déficit o país está tomando empréstimos. Desse modo, denotando por $b_{t+1}$ o valor dos ativos externos de uma economia no final do período $t$, a contacorrente seria definida como:

$$
C A_{t} \stackrel{\stackrel{d e f}{=}}{=} b_{t+1}-b_{t} \stackrel{\text { def }}{=} y_{t}+r \cdot b_{t}-c_{t}-g_{t}-i_{t}
$$

onde $r$ é a taxa de juros internacional que se admite fixa, $b$ é o nível de ativos estrangeiros possuídos pela economia, de modo que r. $b_{t}$ é o pagamento líquido de fatores, que consiste nos juros e dividendos líquidos ganhos sobre ativos estrangeiros, $y$ é o produto interno bruto (PIB), i é o investimento e g representa os gastos do governo, admitindo-se que o orçamento do governo seja sempre equilibrado.

Admite-se que a função utilidade seja quadrática, com a forma $u\left(c_{t}\right)=c_{t}-c_{t}^{2} / 2$, o que requer que $c_{t}<1$ para que a utilidade marginal do consumo seja sempre não negativa.

Resolvendo-se o problema do planejador central, maximizando a equação 1 , sujeito à restrição orçamentária intertemporal, dada pela equação 2 , e considerando-se a condição de transversalidade que garante que não ocorre jogo de Ponzi (nenhum país consegue ter sua dívida crescendo indefinidamente), obtémse a seguinte equação para a trajetória do consumo ótimo:

$$
c_{t}^{*}=\frac{r}{(1+r) \theta}\left[(1+r) b_{t}+\sum_{j=0}^{\infty}\left(\frac{1}{1+r}\right)^{j} E_{t}\left\{Z_{t+j}\right\}\right]
$$

com $\theta=\frac{\beta(1+r) r}{\beta(1+r)^{2}-1}$ e onde $Z_{t+j}=y_{t+j}-i_{t+j}-g_{t+j}$ é o produto líquido de investimentos e dos gastos do governo, frequentemente chamado de produto líquido ou fluxo de caixa nacional.

O parâmetro $\theta$ é a constante de proporcionalidade que reflete a dinâmica da tendência do consumo, o qual é proporcional ao produto líquido. Pode-se observar que quando $\beta=(1+\mathrm{r})^{-1}$ tem-se $\theta=1$, ou seja, não há componente de tendência 
do consumo na conta-corrente. Por outro lado, quando $\theta<1$ (ou $\beta>(1+r)^{-1}$ ), o país está consumindo mais do que seu produto líquido permanente corrente, isto é, está direcionando o consumo para o presente. E se $\theta>1$ (ou $\left.\beta<(1+r)^{-1}\right)$, o país está direcionando o consumo para o futuro, uma vez que está consumindo um valor menor do que seu produto líquido permanente.

A equação 3 mostra que o setor privado consome uma proporção fixa da riqueza total esperada, descontada dos gastos do governo e dos investimentos esperados, ideia associada à teoria da renda permanente, considerando-se os juros fixos.

O principal foco de nossa análise é o componente de suavização de consumo da conta-corrente. Assim, eliminam-se as tendências de longo prazo em relação à poupança em ativos estrangeiros para se concentrar na dinâmica de curto prazo da conta-corrente em torno dessa tendência. Uma vez que não há razão para supormos que o parâmetro $\theta$ de tendência do consumo será sempre igual à unidade, é necessário retirar a tendência dos dados da conta-corrente. A remoção desse componente irá permitir que se identifique corretamente a componente de suavização de consumo da conta-corrente, para a qual o modelo está direcionado.

Dessa forma, a conta-corrente ótima é definida como:

$$
C A_{t}^{*} \stackrel{\text { def }}{=} y_{t}-r . b_{t}-g_{t}-i_{t}-\theta c_{t}^{*}
$$

Ou seja, é a conta-corrente que considera o consumo ótimo e o valor do parâmetro $\theta$. Ao incluir $\theta$ na equação, exclui-se a tendência do consumo, permanecendo apenas o componente de suavização.

Após a substituição de (3) na equação 4 e algumas manipulações algébricas, obtém-se:

$$
C A_{t}^{*}=-\sum_{j=2}^{\infty}\left(\frac{1}{(1+r)}\right)^{j} E_{t}\left\{\Delta Z_{t+j}\right\}
$$

A equação 5 mostra que a conta-corrente ótima é igual a menos o valor presente de mudanças esperadas no produto líquido nacional. ${ }^{1}$ Por exemplo, se os agentes econômicos esperam um aumento nos gastos públicos, há uma variação negativa no produto líquido, proporcionando um superávit na contacorrente. Assim, a conta-corrente atua como um instrumento para a suavização do consumo. A equação 5 também mostra que os agentes econômicos de um país poupam, na forma de ativos estrangeiros, quando esperam queda futura do produto líquido. Dessa forma, choques permanentes no produto líquido, ou nos seus componentes, não terão efeito sobre a conta-corrente, porque o seu

$1 \quad$ A equação 5 é similar à expressão de Campbell (1987) para a poupança do indivíduo como o valor presente esperado de variações futuras de sua renda. 
valor esperado é zero. Por outro lado, choques transitórios levam a flutuações na conta-corrente, e a extensão do movimento da conta-corrente é uma função que decresce com a persistência do choque.

\section{Modelo Econométrico da Conta-Corrente Ótima}

A equação 5 mostra que é necessário estimar o valor presente das mudanças esperadas no produto líquido, sendo o valor esperado condicionado ao conjunto de informações usadas pelos agentes econômicos. Essa tarefa seria muito difícil porque, em geral, o conjunto de informações usadas pelos agentes para previsões futuras dessas variáveis não é conhecida pelo pesquisador. Contudo, o conhecimento exato de qual informação está sendo empregada pelo agente não é necessário. Isso se dá porque, conforme mostrado por Campbell e Shiller (1987) em um diferente contexto, a própria conta-corrente reflete toda a informação disponível para os agentes com o propósito de previsão dessas variáveis. Assim, através da inclusão da conta-corrente no conjunto de informações condicionais, é possível capturar as expectativas dos agentes para choques no produto, investimento e gastos do governo.

Seguindo Campbell e Shiller (1987), é estimado um vetor autorregressivo irrestrito (VAR) em $\left[\Delta Z_{t}, C A_{t}\right]$, onde $Z_{t}=y_{t}-i_{t}-g_{t}$ e $C A_{t}$ é a conta-corrente real sem a tendência do consumo, definida analogamente à equação 4 como:

$$
C A_{t} \stackrel{\text { def }}{=} y_{t}-r \cdot b_{t}-g_{t}-i_{t}-\theta c_{t}
$$

Dessa forma, é necessária uma estimação de $\theta$ para se gerar a série de contacorrente $C A_{t}$. Uma vez que a conta-corrente real dada pela equação 6 é estacionária, o valor de $\theta$ pode ser obtido como o parâmetro de cointegração entre o consumo $c_{t}$ e o produto líquido que considera o pagamento de juros e é dado por $P n b_{t}-i_{t}-g_{t}$, onde o $P n b_{t}=y_{t}-r \cdot b_{t}$.

O cálculo do valor presente das mudanças esperadas no produto líquido para se gerar a série da conta-corrente ótima é feito por meio da estimação do vetor autorregressivo irrestrito de ordem $p$ que no caso específico de $p=1$ assume a forma: ${ }^{2}$

$$
\left[\begin{array}{l}
\Delta Z_{t} \\
C A_{t}
\end{array}\right]=\left[\begin{array}{ll}
a_{11} & a_{12} \\
a_{21} & a_{22}
\end{array}\right]\left[\begin{array}{l}
\Delta Z_{t-1} \\
C A_{t-1}
\end{array}\right]+\left[\begin{array}{l}
e_{1 t} \\
e_{2 t}
\end{array}\right]
$$

Na equação $7, e_{1 t}(i=1,2)$ são erros com média condicional zero, e $\Delta Z_{t} \mathrm{e}$ $C A_{t}$ são expressos como desvios em torno de sua média. Todas as informações disponíveis para os consumidores são capturadas ao se usarem os valores atuais

2 A generalização para ordens maiores do VAR pode ser vista em Senna e Issler (2000). 
e defasados da conta-corrente junto com as informações sobre as variações do produto líquido.

A partir da equação 7 chega-se na expressão para a conta-corrente ótima, a qual é derivada em Sheffrin e Woo (1990), Ghosh (1995) e Senna e Issler (2000) e fornece a série de desvios da conta-corrente ótima em torno de sua média:

$$
C A_{t}^{*}=k\left[\begin{array}{l}
\Delta Z_{t} \\
C A_{t}
\end{array}\right]
$$

onde:

$$
k=-h\left(\frac{1}{1+r} A\right)\left(I-\frac{1}{1+r} A\right)^{-1}
$$

Na equação $9, h=\left[\begin{array}{ll}1 & 0\end{array}\right], A$ é a matriz $2 \times 2$ dos coeficientes do modelo mostrado na equação 7 e I é uma matriz identidade $2 \times 2$. Com base na equação 8 , supondo-se que as variações da série da conta-corrente ótima e da série real em torno de suas respectivas médias sejam iguais, devemos ter que $\left[k_{11} k_{12}\right]=[01]$, ou seja, o coeficiente $k_{11}$ deve ser nulo para o produto líquido e $k_{12}$ deve ser unitário para a conta-corrente. Essa restrição aos elementos da matriz $k$, quando aplicada no lado direito da equação 9, permite que se derive também as restrições impostas aos coeficientes individuais da matriz $A$ do VAR e que podem ser testadas usandose um teste de Wald: ${ }^{3}$

$$
\begin{gathered}
a_{11}=a_{21} \\
a_{22}=(1+r)+a_{12}
\end{gathered}
$$

O teste de restrição nos coeficientes da matriz A do VAR é uma forma de se avaliar se os desvios em relação à média das séries da conta-corrente real e da conta-corrente estimada são estatisticamente equivalentes.

Além disso, uma vez que a série da conta-corrente ótima foi calculada, é possível comparar a sua variância com a da série real para se avaliar se as variações da conta-corrente real são suficientes para permitir a suavização do consumo e também calcular a correlação entre as duas séries para determinar se os movimentos da conta-corrente real são consistentes com os preditos pelo modelo intertemporal de suavização de consumo.

Em resumo, nas próximas seções serão avaliadas as quatro implicações do modelo intertemporal da conta-corrente que foram originalmente propostas por Sheffrin e Woo (1990) e Otto (1992):

A demonstração desse resultado pode ser vista em Senna e Issler (2000). 
a) a estacionariedade da série de conta-corrente real em nível;

b) se a conta-corrente causa no sentido de Granger variações no produto líquido;

c) se as restrições dos coeficientes do VAR obtidos na estimação da conta-corrente ótima são válidas;

d) se existe uma relação próxima entre a série de conta-corrente real e a série ótima estimada a partir do VAR: comparação da volatilidade das séries e estimação da correlação entre elas.

\subsection{A Função Impulso Resposta da Conta-Corrente}

A função de resposta ao impulso da conta-corrente a choques com efeitos temporários e permanentes no produto líquido foi obtida empregando-se a metodologia proposta por Blanchard e Quah (1989). Aplicando-se essa metodologia na análise intertemporal da conta-corrente, busca-se decompor o produto líquido $Z_{t}$ em seus componentes temporário e permanente, uma vez que o modelo intertemporal estabelece que apenas choques com efeitos temporários no produto líquido provocam flutuações na conta-corrente.

Para decompor as séries $Z_{t}$ e $C A_{t}$ em seus componentes temporário e permanente, podemos inicialmente representar as séries como uma média móvel bivariada (ENDERS, 2010):

$$
\begin{gathered}
\Delta Z_{t}=\sum_{k=0}^{\infty} c_{11}(k) \varepsilon_{1 t-k}+\sum_{k=0}^{\infty} c_{12}(k) \varepsilon_{2 t-k} \\
C A_{t}=\sum_{k=0}^{\infty} c_{21}(k) \varepsilon_{1 t-k}+\sum_{k=0}^{\infty} c_{22}(k) \varepsilon_{2 t-k}
\end{gathered}
$$

que pode ser escrita de uma forma mais compacta como:

$$
\left[\begin{array}{l}
\Delta Z_{t} \\
C A_{t}
\end{array}\right]=\left[\begin{array}{ll}
C_{11}(L) & C_{12}(L) \\
C_{21}(L) & C_{22}(L)
\end{array}\right]\left[\begin{array}{l}
\varepsilon_{1 t} \\
\varepsilon_{2 t}
\end{array}\right]
$$

onde $\varepsilon_{1 t}$ e $\varepsilon_{2 t}$ são ruídos brancos independentes e com variância constante; $C_{i j}(L)$ são polinômios no operador de defasagem $L$ com coeficientes individuais denotados por $c_{i j}(k)$. Para se aplicar a técnica de Blanchard e Quah, pelo menos uma das variáveis deve ser não estacionária, uma vez que variáveis $I(0)$ não possuem uma componente permanente. Contudo, para usar o método, todas as variáveis devem estar em suas formas estacionárias. Uma vez que a série $Z_{t}$ é I(1), a equação 14 emprega a sua primeira diferença.

Diferentemente do procedimento para decomposição proposto por SimsBernanke, Blanchard e Quah não associam diretamente os choques $\varepsilon_{1 t}$ e $\varepsilon_{2 t} \mathrm{com}$ 
as séries $\Delta Z_{t}$ e $C A_{t}$. Ao invés disso, as séries $\Delta Z_{t}$ e $C A_{t}$ são variáveis endógenas e as sequências $\varepsilon_{1 t}$ e $\varepsilon_{2 t}$ representam as variáveis exógenas.

Define-se $\varepsilon_{1 t}$ e $\varepsilon_{2 t}$, respectivamente, como choques temporários e permanentes no produto líquido $Z_{t^{*}}$. Para se obter a identificação completa das inovações estruturais do VAR estimado, assume-se a restrição, na equação 14, de que choques temporários não têm efeito de longo prazo sobre o produto líquido:

$$
\sum_{k=0}^{\infty} c_{11}(k) \varepsilon_{1 t-k}=0
$$

Uma vez que essa restrição deve valer para qualquer realização possível de $\varepsilon_{1}$, deve-se ter que:

$$
\sum_{k=0}^{\infty} c_{11}(k)=0
$$

Dessa forma, tem-se que o efeito de longo prazo de $\varepsilon_{1 t}$ sobre o nível do produto líquido é zero, ou seja, tem apenas efeitos de curto prazo sobre $\Delta Z_{t}$ e, por conseguinte, provoca flutuações na conta-corrente.

Uma vez que $\varepsilon_{1 t}$ e $\varepsilon_{2 t}$ não são observáveis, o problema consiste em recuperálos a partir de uma estimação de VAR. Dado que $\Delta Z_{t}$ e $C A_{t}$ são variáveis estacionárias, sabe-se que existe uma representação VAR na forma:

$$
\left[\begin{array}{l}
\Delta Z_{t} \\
C A_{t}
\end{array}\right]=\left[\begin{array}{ll}
A_{11}(L) & A_{12}(L) \\
A_{21}(L) & A_{22}(L)
\end{array}\right]\left[\begin{array}{l}
\Delta Z_{t-1} \\
C A_{t-1}
\end{array}\right]+\left[\begin{array}{l}
e_{1 t} \\
e_{2 t}
\end{array}\right]
$$

onde $A_{i j}(L)$ são polinômios do operador de defasagem $L$ e $e_{1 t}$ e $e_{2 t}$ são os erros de previsão um passo à frente de $\Delta Z_{t}$ e $C A_{t}$ A relação entre os erros de previsão e os choques estruturais é dada por:

$$
\left[\begin{array}{l}
e_{1 t} \\
e_{2 t}
\end{array}\right]=\left[\begin{array}{ll}
c_{11}(0) & c_{12}(0) \\
c_{21}(0) & c_{22}(0)
\end{array}\right]\left[\begin{array}{l}
\varepsilon_{1 t} \\
\varepsilon_{2 t}
\end{array}\right]
$$

Blanchard e Quah mostram que a relação (equação 17), o modelo bivariado de média móvel (equação 14) e a restrição de longo prazo (equação 16) fornecem exatamente quatro restrições que podem ser usadas para identificar os quatro coeficientes $c_{i j}(0)$ :

$$
\begin{gathered}
\operatorname{var}\left(e_{1}\right)=c_{11}(0)^{2}+c_{12}(0)^{2} \\
\operatorname{var}\left(e_{2}\right)=c_{21}(0)^{2}+c_{22}(0)^{2} \\
\operatorname{cov}\left(e_{1}, e_{2}\right)=c_{11}(0) c_{21}(0)+c_{12}(0) c_{22}(0) \\
0=c_{11}(0)\left[1-\sum a_{22}(k)\right]+c_{21}(0) \sum a_{12}(k)
\end{gathered}
$$


Se $c_{11}(0), c_{12}(0), c_{21}(0)$ e $c_{22}(0)$ são conhecidos, é possível recuperar $\varepsilon_{1 t}$ e $\varepsilon_{2 t}$ a partir dos resíduos da regressão $e_{1 t}$ e $e_{2 t}$, empregando-se a equação 18. Como num VAR tradicional, as sequências de $\varepsilon_{1 t}$ e $\varepsilon_{2 t}$ são, então, empregadas para se obter a função de resposta ao impulso.

\section{Estimativas do Modelo}

Este trabalho emprega dados anuais para a economia brasileira referente ao período de 1947 a 2010. Os dados de produto agregado, consumo agregado, gastos do governo, investimento agregado e rendas foram obtidos a partir da base de dados do Ipeadata e a fonte dos dados é o Instituto Brasileiro de Geografia e Estatística (IBGE). Todos os valores foram convertidos a preços constantes por intermédio do deflator implícito do PIB, empregando-se como base o ano de 2010, sendo em seguida transformados para valores per capita.

\subsection{Dados}

Foram utilizadas as seguintes séries: "produto interno bruto", "consumo final das famílias", "consumo final da administração pública", "formação bruta de capital fixo" e "rendas de propriedade enviadas e recebidas do resto do mundo". Todas essas séries estão disponibilizadas em milhões de reais. Todos os valores foram convertidos a preços constantes de um período de referência por intermédio do deflator implícito do PIB, tendo-se como base o ano de 2010. Para essa finalidade, foi empregada a série "produto interno bruto (PIB) - deflator implícito: variação anual". Por último, as séries foram convertidas para valores per capita, empregando-se a série "população residente - total". Uma vez que a série de população está dispovível para cada 10 anos, foi realizada interpolação para se obter a população com periodicidade anual.

\subsection{Testes de Raiz Unitária e Cointegração}

Os Gráficos de 1 a 4 apresentam as séries utilizadas no trabalho. O Gráfico 1 mostra a série da conta-corrente $C A_{t}$. Pode-se observar que esta apresentou valores negativos, em especial, nos seguintes períodos:

a) após o primeiro choque do petróleo, ocorrido em 1973;

b) após o segundo choque do petróleo, ocorrido em 1979, e nos primeiros anos da década de 1980, quando a economia brasileira enfrentou um cenário de recessão e com grandes déficits na balança comercial agravados pelo aumentos do custo das importações de petróleo; e 
c) nos primeiros anos do Plano Real, quando a moeda brasileira valorizada frente ao dólar contribui para os resultados negativos da balança comercial.

No Gráfico 2 mostra-se a série da variação do produto líquido nacional $\Delta Z_{t}$, com destaque para a queda significativa ocorrida no ano de 1987, provavelmente como consequência da moratória brasileira decretada naquele ano. Em relação ao Gráfico 3, uma vez que historicamente o Brasil apresenta um saldo negativo em relação às remessas líquidas de renda para o exterior, observa-se que a série "produto nacional bruto" situa-se abaixo da série "produto interno bruto" no período apresentado. O Gráfico 4 mostra que as séries "consumo das famílias" e $P n b_{t}-i_{t}-g_{t}$ possuem tendência ao longo do tempo, a qual pode estar sendo gerada pela presença de raiz unitária. A cointegração dessas duas séries é um dos pontos que será avaliado neste trabalho.

Gráfico 1 - Conta-corrente $C A_{t}$

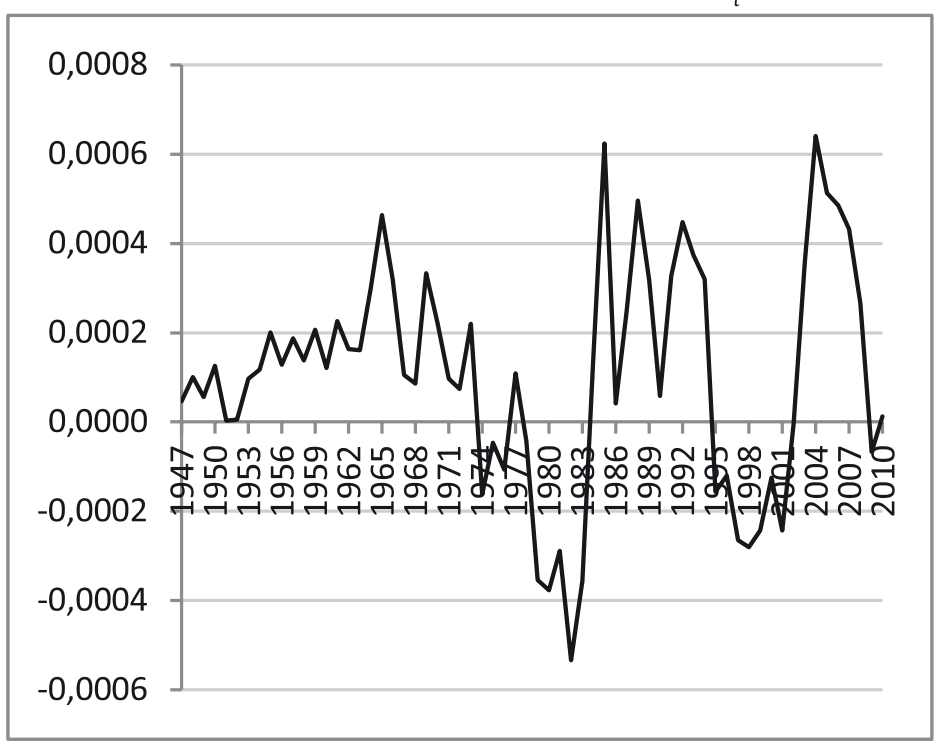

Fonte: Elaboração própria. 
Gráfico 2 - Variação do produto líquido $\Delta Z_{t}$

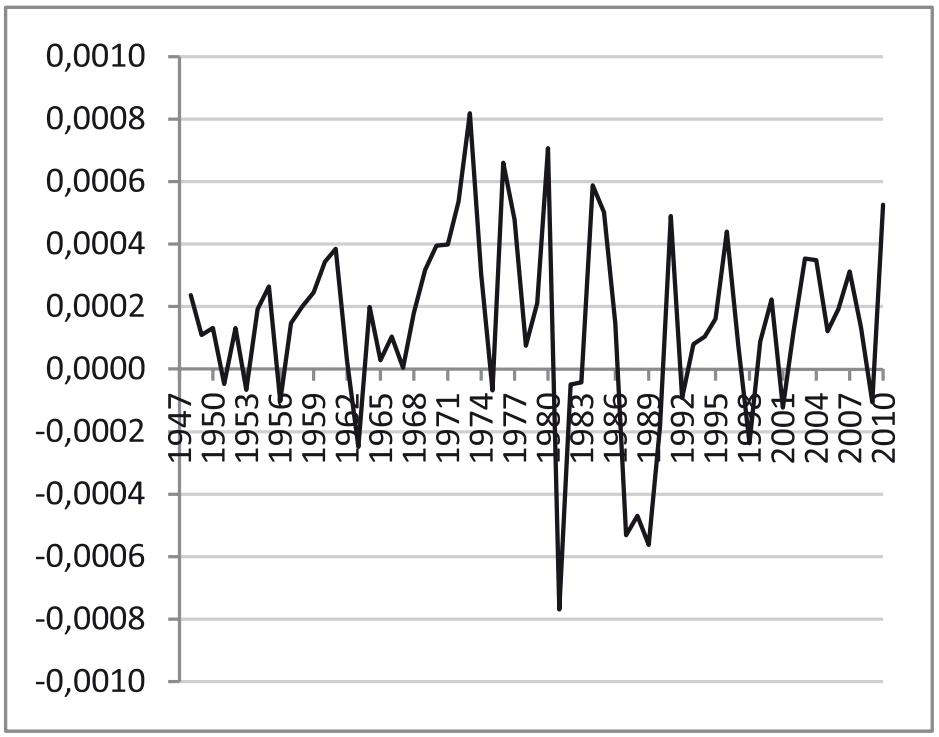

Fonte: Elaboração própria.

Gráfico 3 - PIB, PNB, investimento e gastos do governo

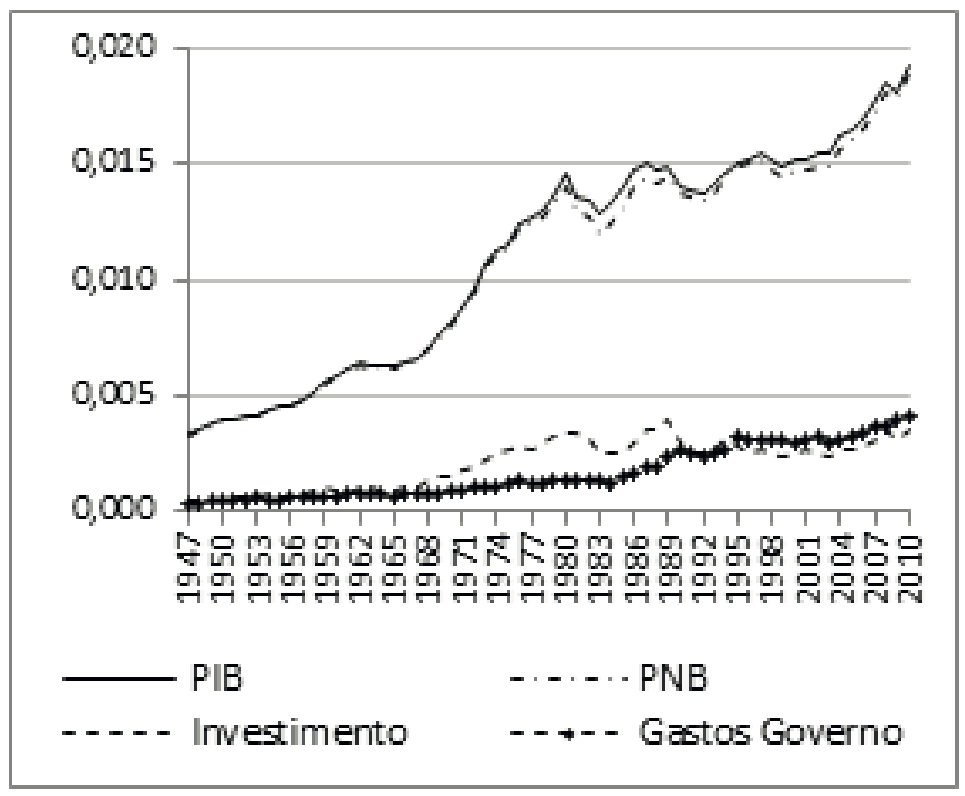

Fonte: Elaboração própria. 
Gráfico 4 - PNB, investimentos, gastos e consumo

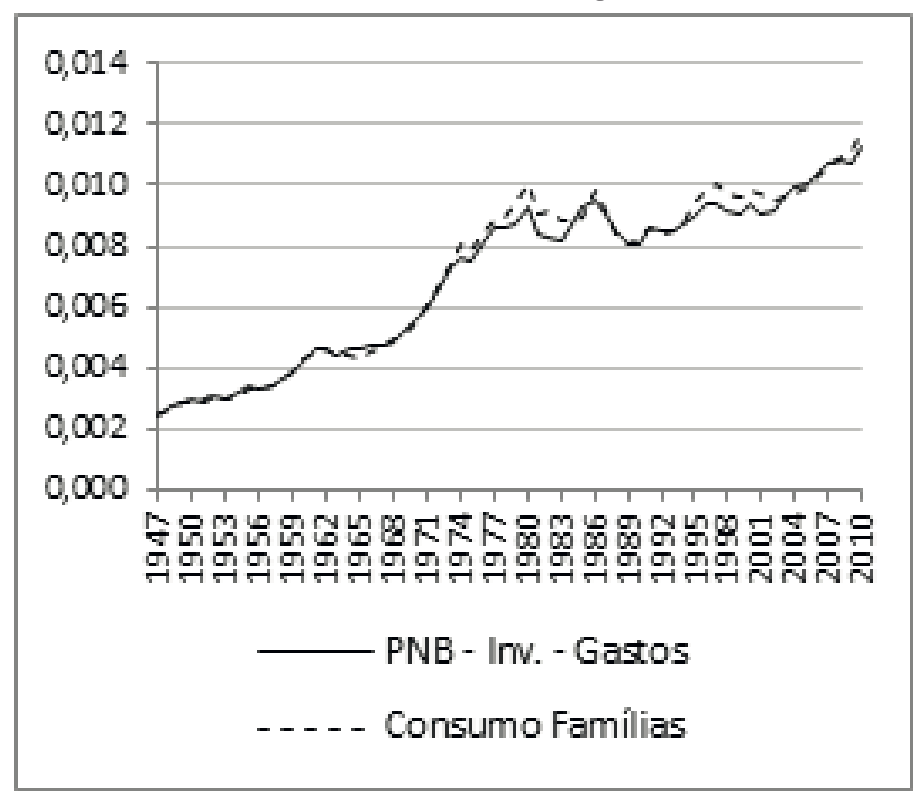

Fonte: Elaboração própria.

Como é usual, inicialmente foram realizados testes para verificar se há presença de raiz unitária nas séries empregadas no modelo. A Tabela 1 apresenta os resultados para os testes de Dickey-Fuller aumentado (ADF), de Dickey-Fuller aumentado com GLS (ADF ${ }^{\mathrm{GLS}}$ ), de Phillips-Perron (PP) e de Kwiatkowski-PhillipsSchmidt-Shin (KPSS) para as variáveis em nível e em primeira diferença. Os resultados dos testes indicam que se pode aceitar a hipótese nula de existência de raiz unitária para as séries em nível do consumo agregado $c_{t}$ gastos do governo $\mathrm{g}_{\mathrm{t}}$, investimento agregado $i_{t}$, produto agregado $y_{t}$, produto líquido nacional $z_{t}$ e para a série $P n b_{t}-i_{t}-g_{t}$. Os testes também evidenciam que se pode não aceitar a hipótese nula no caso da série em nível da conta-corrente $c a_{t}$, o que está de acordo com o que a teoria prevê sobre a estacionariedade dessa série. Para os dados das séries em primeiras diferenças, os resultados sugerem que a hipótese nula de presença de raiz unitária pode não ser aceita a um nível de significância de $5 \%$ em todos os casos, confirmando os resultados de que o consumo agregado, os gastos do governo, o investimento agregado e o produto agregado são séries integradas de primeira ordem ou $I(1)$.

Dessa forma, com base nos resultados apresentados na Tabela 1, será assumido nesse trabalho que a conta-corrente é estacionária e que o consumo, os gastos do governo, os investimentos e o produto possuem uma única raiz unitária, ou seja, são séries I(1). É conhecido que os testes tradicionais de raiz unitária possuem baixo poder na presença de quebras estruturais - mudança exógena na série de tempo, tornando-se enviesados no sentido da não rejeição da hipótese nula de existência de raiz unitária quando a série é estacionária. Uma vez que os resultados apontaram para a estacionariedade da conta-corrente, em nível, e das 
demais séries em suas primeiras diferenças, este trabalho não aplicou um procedimento específico para testar a raiz unitária com a incorporação de quebra estrutural determinada exógena ou endogenamente.

A estacionariedade das séries de $C A_{t}$ e $\Delta Z_{t}$, conforme já era esperado, confirmam a primeira proposição testável do modelo intertemporal da conta-corrente.

Tabela 1 - Teste de raiz unitária das séries ${ }^{1}$

\begin{tabular}{lllll}
\hline Variável & $\begin{array}{c}\text { Teste ADF } \\
\text { Estatistica } t\end{array}$ & $\begin{array}{c}\text { Teste ADFGLS } \\
\text { Estatística } t\end{array}$ & $\begin{array}{c}\text { Teste PP4 } \\
\text { Estatistica } t\end{array}$ & $\begin{array}{c}\text { KPSS }^{5} \\
\text { Estatística } t\end{array}$ \\
\hline$c a_{t}$ & $-2.9795^{* * *}$ & $-2.9449^{* * *}$ & $-2.9795^{* * *}$ & 0.2635 \\
$c_{t}$ & -0.5710 & 0.4898 & -0.6269 & $0.9484^{* * *}$ \\
$\Delta c_{t}$ & $-3.0217^{* * *}$ & $-1.9986^{* * *}$ & $-6.4247^{* * *}$ & 0.0888 \\
$g_{t}$ & 1.3884 & 2.0261 & 1.4963 & $0.9756^{* * *}$ \\
$\Delta g_{t}$ & $-7.0293^{* * *}$ & $-7.0850^{* * *}$ & $-7.0341^{* * *}$ & $0.3866^{*}$ \\
$i_{t}$ & -1.0627 & -0.0381 & -0.9717 & $0.8363^{* * *}$ \\
$\Delta i_{t}$ & $-6.7824^{* * *}$ & $-6.7928^{* * *}$ & $-6.6869^{* * *}$ & 0.1018 \\
$y_{t}$ & -0.2562 & 0.9503 & -0.1929 & $0.9877^{* * *}$ \\
$\Delta y_{t}$ & $-3.7348^{* * *}$ & $-3.7441^{* * *}$ & $-5.6806^{* * *}$ & 0.0858 \\
$z_{t}$ & -0.6409 & 1.0032 & -0.7393 & $0.9571^{* * *}$ \\
$\Delta z_{t}$ & $-5.9731^{* * *}$ & $-5.7911^{* * *}$ & $-5.9879 * * *$ & 0.1072 \\
$\left(p n b_{t}-i_{t}-g_{t}\right)$ & -0.6005 & 1.0046 & -0.6769 & $0.9652^{* * *}$ \\
$\Delta\left(\right.$ pnb $\left._{t}-i_{t}-g_{t}\right)$ & $-6.0104^{* * *}$ & $-5.8374^{* * *}$ & $-5.9014^{* * *}$ & 0.0881 \\
\hline
\end{tabular}

Fonte: Elaboração própria.

Notas: ${ }^{1}$ Foram empregadas equações de teste com intecepto. Significâncias a 1\%, 5\% e 10\% são representadas por ${ }^{* * *},{ }^{* *} \mathrm{e} *$, respectivamente; ${ }^{2} \mathrm{e}^{3}$ Foi empregado o critério de informação de Akaike modificado com seleção automática para se obter a defasagem ótima; ${ }^{3}$ Valores críticos: -2.6022 (1\%), -1.9461 (5\%) e -1.6134 (10\%); ${ }^{4}$ Foi empregado o método de estimação de Newey-West com Kernel Bartlett para a largura de banda; ${ }^{5} \mathrm{O}$ teste KPSS tem como hipótese nula a estacionariedade da série; Valores críticos: 0.7390 (1\%), 0.4630 (5\%) e 0.3470 (10\%).

Dadas as relações de longo prazo entre $c_{t}$ e $P n b_{t}-i_{t}-g_{t}$, o valor de $\theta$, que é o parâmetro de tendência do consumo, é obtido a partir do vetor cointegrante dessas duas séries. A escolha do número de defasagens do VAR foi baseada nos critérios de informação apresentados na Tabela 2. Verificou-se que o número de defasagens mais apropriado para o VAR é um. A Tabela 3 mostra os resultados obtidos para o teste de cointegração das variáveis com a aplicação da metodologia de Johansen. A um nível de significância de $10 \%$, as estatísticas $\lambda_{\text {traço }}$ e $\lambda_{\max }$ sugerem que o número de vetores de cointegração é igual a um, estimado em [1.0000, -0.9647].

Também foi efetuado o teste de cointegração baseado na metodologia de Engle-Granger. A Tabela 4 mostra os resultados da regressão da série $P n b_{t}-i_{t}-g_{t}$, 
empregando-se $c_{t}$ como regressor. A Tabela 5 apresenta o teste de raiz unitária para os resíduos estimados dessa regressão. Uma vez que não foi observada autocorrelação nos resíduos $\varepsilon_{t}$, não houve necessidade de estimar o modelo aumentado. Observa-se que a hipótese nula de presença de raiz unitária, ou de não haver cointegração, é rejeitada para um nível de significância de 5\%, reforçando o resultado obtido com o teste de Johansen. Com a metodologia de Engle-Granger, o valor estimado para $\theta$ foi de 0.949860 .

O valor obtido para o parâmetro $\theta$ abaixo da unidade indica a presença de uma componente de tendência no consumo para o caso brasileiro. Ou seja, o país consome uma quantidade superior ao seu produto líquido permanente, antecipando consumo. A série de conta-corrente empregada no trabalho é calculada considerando-se esse componente de tendência de consumo. Ao incluir o parâmetro $\theta$ na equação 4 , a tendência do consumo é eliminada, com o objetivo de se trabalhar apenas o componente de suavização. No decorrer do trabalho será empregado o valor de $\theta$ igual a 0.964744 , obtido a partir do teste de Johansen.

Tabela 2 - Ordem ótima do VAR para análise de cointegração entre $c_{t}$ e $P n b_{t}-i_{t}-g_{t}$

\begin{tabular}{lccccc}
\hline Lag & LR & FPE & AIC & SC & HQ \\
\hline 1 & NA & $4.09 \mathrm{e}-15^{*}$ & $-27.45371^{*}$ & $-27.31408^{*}$ & $-27.39909^{*}$ \\
2 & 4.538449 & $4.31 \mathrm{e}-15$ & -27.40142 & -27.12217 & -27.29219 \\
3 & 6.002259 & $4.42 \mathrm{e}-15$ & -27.37924 & -26.96037 & -27.21539 \\
\hline
\end{tabular}

Fonte: Elaboração própria.

Notas: * indica o número de defasagens selecionado pelo critério; LR: estatística de teste LR modificada sequencial (cada teste ao nível de 5\%); FPE: erro de predição final; AIC: critério de informação Akaike; SC: critério de informação Schwarz; HQ: critério de informação de Hannan-Quinn.

Tabela 3 - Teste de cointegração de Johansen entre $c_{t}$ e $P n b_{t}-i_{t}-g_{t}$

\begin{tabular}{lccccccc}
\hline & & \multicolumn{3}{c}{$\lambda_{\text {traço }}$} & \multicolumn{3}{c}{$\lambda_{\max }$} \\
\cline { 3 - 8 } $\begin{array}{l}N^{*} \text { de vetores } \\
\text { cointegrantes }\end{array}$ & $\begin{array}{c}\text { Auto- } \\
\text { valor }\end{array}$ & $\begin{array}{c}\text { Estatís- } \\
\text { tica }\end{array}$ & $\begin{array}{c}\text { Valor cri- } \\
\text { tico 5\% }\end{array}$ & p-valor & $\begin{array}{c}\text { Estatís- } \\
\text { tica }\end{array}$ & $\begin{array}{c}\text { Valor crí- } \\
\text { tico 5\% }\end{array}$ & p-valor \\
\hline Nenhum & 0.1867 & 16.8134 & 12.3209 & 0.0083 & 12.8185 & 11.2248 & 0.0260 \\
No máximo um & 0.0624 & 3.9949 & 4.12991 & 0.0541 & 3.99489 & 4.12991 & 0.0541 \\
\hline
\end{tabular}

Fonte: Elaboração própria. 
Tabela 4 - Estimação da equação $P n b_{t}-i_{t}-g_{t}=\alpha+\theta c_{t}+e_{t}$

\begin{tabular}{lccc}
\hline Parâmetro & Estimação & Estatística & p-valor \\
\hline$\alpha$ & 0.000212 & 2.407748 & 0.0190 \\
$\theta$ & 0.949860 & 82.82160 & 0.0000 \\
$\mathrm{R}^{2}$ & 0.991042 & & \\
$\mathrm{R}^{2}$ ajustado & 0.990898 & & \\
\hline
\end{tabular}

Fonte: Elaboração própria.

Tabela 5 - Teste de raiz unitária dos resíduos estimados: $\Delta \hat{e}_{t}=\alpha \hat{e}_{t-1}+\varepsilon_{t}$

\begin{tabular}{lcccc}
\hline & & \multicolumn{3}{c}{ Valores críticos para a hipótese nula de raiz } \\
Unitária
\end{tabular}

Fonte: Elaboração própria.

Nota: ${ }^{1}$ Valores críticos obtidos por Engle e Granger (1987).

\subsection{Estimação do Modelo VAR}

Uma vez verificada a existência de cointegração entre as séres $c_{t} \mathrm{e}$ $P n b_{t}-i_{t}-g_{t}$, é possível estimar um VAR irrestrito com $C A_{t}$ e $\Delta Z_{t}$. A escolha do número de defasagens do VAR é baseada nos critérios de informação apresentados na Tabela 6. Dada a divergência entre os critérios, optou-se pela alternativa mais parcimoniosa, empregando-se uma única defasagem para a estimação do VAR.

Tabela 6 - Ordem ótima do VAR

\begin{tabular}{lccccc}
\hline Lag & LR & FPE & AIC & SC & HQ \\
\hline 1 & NA & $4.78 \mathrm{e}-15$ & -27.29941 & $-27.15071^{*}$ & $-27.24223^{*}$ \\
2 & 5.799991 & $4.94 \mathrm{e}-15$ & -27.26684 & -26.96943 & -27.15247 \\
3 & 2.246118 & $5.48 \mathrm{e}-15$ & -27.16368 & -26.71758 & -26.99213 \\
4 & 1.071585 & $6.24 \mathrm{e}-15$ & -27.03655 & -26.44175 & -26.80782 \\
5 & 12.06540 & $5.51 \mathrm{e}-15$ & -27.16620 & -26.42269 & -26.88028 \\
6 & 10.45962 & $5.00 \mathrm{e}-15$ & -27.27037 & -26.37816 & -26.92727 \\
7 & $10.62730^{*}$ & $4.47 \mathrm{e}-15$ & -27.39192 & -26.35101 & -26.99164 \\
8 & 7.021998 & $4.35 \mathrm{e}-15^{*}$ & $-27.43076^{*}$ & -26.24115 & -26.97329 \\
\hline
\end{tabular}

Fonte: Elaboração própria.

Notas: * indica o número de lags selecionado pelo critério; LR: estatística de teste LR modificada sequencial (cada teste ao nível de 5\%); FPE: erro de predição final; AIC: critério de informação Akaike; SC: critério de informação Schwarz; HQ: critério de informação de Hannan-Quinn. 
Procedeu-se, então, a estimativa do VAR. Os coeficientes estimados, bem como os desvios padrões e as estatísticas $t$ associadas estão apresentados na Tabela 7. Observa-se que os coeficientes de $C A_{t-1}$ na equação de $\Delta Z_{t}$ e os coeficientes de $\Delta Z_{t-1}$ na equação de $C A_{t}$ não são individualmente significativos a partir da estatística $t$, o que sugere que a conta-corrente não Granger causa variações no produto líquido $Z$ e que variações em $Z$ não Granger causa variações em $C A$. Para confirmação da ausência de causalidade é efetuado o teste formal da causalidade de Granger que está apresentado na Tabela 8. Esse teste indica a não rejeição da hipótese nula de não causalidade nos dois sentidos, contrariando a segunda proposição testável do modelo intertemporal da conta-corrente. Ou seja, a partir dos resultados obtidos, não se pode inferir que a conta-corrente do Brasil ajuda a prever variações no produto líquido.

Tabela 7 - Estimação do VAR ${ }^{1}$

\begin{tabular}{lcc}
\hline \multirow{2}{*}{ Regressor } & Equação 1 & Equação 2 \\
\hline \multirow{2}{*}{$\Delta \boldsymbol{Z}_{t-1}$} & $\Delta \boldsymbol{Z}_{\boldsymbol{t}}=\boldsymbol{a}_{11} \Delta \boldsymbol{Z}_{\boldsymbol{t}-1}+\boldsymbol{a}_{12} \boldsymbol{C} \boldsymbol{A}_{\boldsymbol{t}-1}$ & $\boldsymbol{C} \boldsymbol{A}_{\boldsymbol{t}}=\boldsymbol{a}_{21} \Delta \boldsymbol{Z}_{\boldsymbol{t}-1}+\boldsymbol{a}_{22} \boldsymbol{C A}_{\boldsymbol{t}-1}$ \\
\multirow{2}{*}{$A_{t-1}$} & $0.2496^{* * *}$ & 0.0149 \\
& $(0.1282)$ & $(0.0829)$ \\
Constante & -0.0938 & $0.6845^{* * *}$ \\
& $(0.1475)$ & $(0.0953)$ \\
& 0.0001 & $3.05 \mathrm{E}-05$ \\
& $(4.4 \mathrm{E}-05)$ & $(2.8 \mathrm{E}-05)$ \\
\hline
\end{tabular}

Fonte: Elaboração própria.

Nota: ${ }^{1}$ Significâncias a $1 \%, 5 \%$ e $10 \%$ são representadas por * ** * * $\mathrm{e}^{*}$, respectivamente. Os desvios padrões são apresentados entre parênteses.

Tabela 8 - Teste de causalidade de Granger

\begin{tabular}{lcc}
\hline Hipótese nula & Estatística $\mathbf{F}$ & p-valor \\
\hline$\Delta Z_{t}$ não Granger causa $C A_{t}$ & 0.0323 & 0.8579 \\
$C A_{t}$ não Granger causa $\Delta Z_{t}$ & 0.4046 & 0.5272 \\
\hline
\end{tabular}

Fonte: Elaboração própria.

Para compararmos os valores estimados para a conta-corrente ótima com os valores observados, é necessário testar as restrições impostas aos coeficientes do VAR. Conforme apresentado na seção 4, que descreveu o modelo econométrico, pretende-se testar se no VAR definido pela equação 17 os coeficientes obtidos obedecem às restrições dadas pelas equações 10 e 11, com o objetivo de se avaliar se as séries da conta-corrente real e da conta-corrente estimada são estatisticamente equivalentes. 
Essas restrições são conjuntamente testadas pelo teste de Wald, que tem distribuição qui-quadrado, com o número de graus de liberdade igual ao número de restrições impostas. O resultado do teste é apresentado na Tabela 9 e pode-se observar que as igualdades não são rejeitadas, indicando que as séries de contacorrente ótima e real são estatisticamente iguais. Assim, tem-se a confirmação da terceira proposição testável do modelo intertemporal da conta-corrente, ou seja, o Brasil consegue utilizar a conta-corrente como instrumento para suavizar o consumo intertemporalmente.

Tabela 9 - Teste de Wald sobre as restrições dos parâmetros do VAR

\begin{tabular}{cc}
\hline Estatística $\chi \mathbf{2}$ (2) & p-valor \\
\hline 4.7196 & 0.0944 \\
\hline
\end{tabular}

Fonte: Elaboração própria.

\subsection{Estimação da Conta-Corrente Ótima e Comparação com a Observada}

Para a comparação entre a série da conta-corrente ótima $C A_{t}^{*}$ com a série da conta-corrente real da economia brasileira $C A_{t^{\prime}}$, efetua-se a estimação da série ótima empregando-se a equação 8 , com as duas séries calculadas como a variação em torno de suas respectivas médias. Empregou-se uma taxa de juros internacional de $2 \%$. Segundo Otto (1992), o uso de uma taxa de juros na faixa entre $2 \%$ e $8 \%$ não afeta de forma significativa o resultado dos testes. A série para as variações da conta-corrente ótima em torno da sua média a partir do VAR é dada por:

$$
C A_{t}^{*}-\mu_{C A^{*}}=0.3168\left(\Delta Z_{t-1}-\mu_{\Delta Z}\right)+0.3682\left(C A_{t-1}-\mu_{C A}\right)
$$

A conta-corrente real foi obtida a partir da equação 6, calculando-se em seguida os seus desvios em relação à média. As duas séries são apresentadas no Gráfico 5. Pode-se observar que, em geral, a série de conta-corrente real atinge valores absolutos mais elevados do que a série ótima. Ou seja, a conta-corrente real apresenta sempre maiores superávits ou déficits do que a conta-corrente ótima. As maiores diferenças podem ser observadas nos primeiros anos da década de 1980, na segunda metade da década de 1990 e após o ano de 2004, e o fraco ajuste pode estar relacionado a períodos de crises em que se teria maiores dificuldades para acessar o mercado internacional. 
Gráfico 5 - Conta-corrente ótima $C A_{t}^{*}$ e real $C A_{t}$

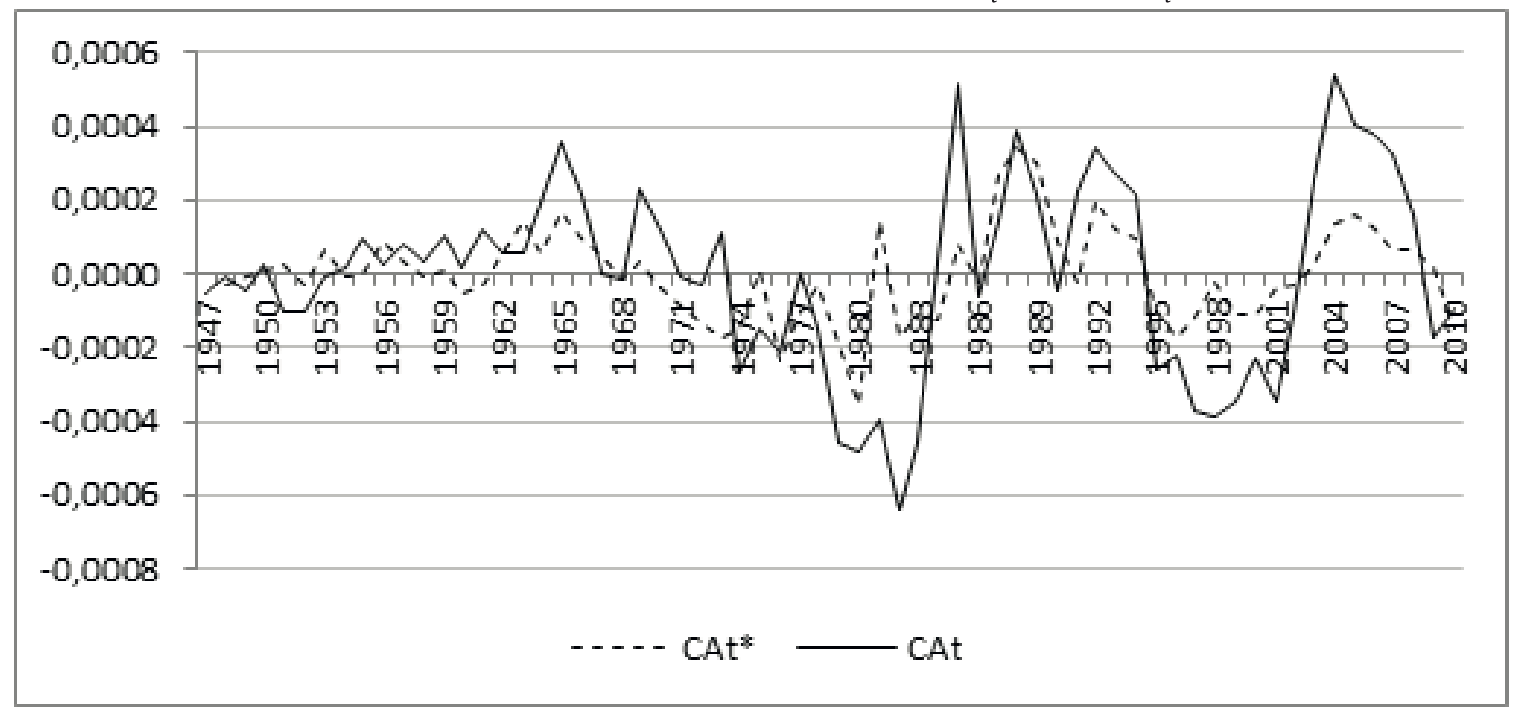

Fonte: Elaboração própria.

Em relação à volatilidade das séries, nota-se que a conta-corrente real é mais volátil do que a conta-corrente ótima. Os autores que utilizam o modelo de suavização de consumo para medir o grau de mobilidade de capitais afirmam que esse fato pode ser explicado pelo grande fluxo de capitais especulativos no país. O nível ótimo de fluxo de capitais é o que permitiria aos agentes econômicos suavizarem o consumo, na presença de choques esperados no produto líquido, e a conta-corrente ótima seria aquela que permitiria essa suavização do consumo. Se a conta-corrente real apresenta movimentos excessivos, o fluxo de capitais é maior do que o fluxo que seria justificado por mudanças esperadas no produto líquido, o que poderia ser causado por maiores fluxos de capitais de curto prazo em resposta a movimentos especulativos.

A Tabela 10 apresenta o desvio padrão das séries de conta-corrente real e de conta-corrente ótima e a correlação entre as séries. O coeficiente de correlação estimado foi 0.6739 , o que indica que as duas séries variam no mesmo sentido e estão relativamente próximas. Assim, conclui-se a verificação da quarta proposição testável do modelo intertemporal da conta-corrente.

Tabela 10 - Desvio padrão e correlação de $\mathrm{CA}_{\mathrm{t}}$ e $\mathrm{CA}_{\mathrm{t}}$ *

\begin{tabular}{|c|c|c|c|c|}
\hline DP $\left(C A_{t}\right)$ & $\mathrm{DP}\left(\mathrm{CA}_{\mathrm{t}}^{*}\right)$ & DP $\left(C A_{t}\right) / D P\left(C A_{t}^{*}\right)$ & $\operatorname{Var}\left(\mathbf{C A}_{t}\right) / \operatorname{Var}\left(\mathrm{CA}_{t}^{*}\right)$ & $\operatorname{Corr}\left(C A_{t}, C A_{t}^{*}\right)$ \\
\hline 0.000254 & 0.000127 & 2.00 & 4.00 & 0.673922 \\
\hline
\end{tabular}

Fonte: Elaboração própria. 


\subsection{Função de Resposta ao Impulso da Conta-Corrente}

Os Gráficos 6 e 7 apresentam a função de resposta ao impulso da contacorrente para choques com efeitos temporários e permanentes sobre o produto líquido $Z_{t}$, respectivamente. Pretende-se verificar com esse exercício se apenas os choques cujo efeito de longo prazo sobre o nível do produto líquido é zero, ou seja, que tem apenas efeitos de curto prazo sobre o produto líquido, provocam flutuações na conta-corrente, conforme estabelece a teoria do modelo intertemporal.

Analisando a função de resposta ao impulso da conta-corrente obtida para choques com efeitos temporários sobre o produto líquido, no Gráfico 6, percebese que eles têm impacto inicial positivo sobre a conta-corrente, conforme previsto pelo modelo intertemporal. A função de resposta ao impulso mostra que o choque tende a desaparecer após o sexto ano.

Em relação aos choques com efeitos permanentes sobre o produto líquido, verifica-se que não afetam a conta-corrente significativamente e, portanto, os resultados obtidos mostram-se coerentes com a predição teórica de que a contacorrente somente é afetada por choques com efeitos temporários sobre o produto líquido.

Gráfico 6 - Resposta da conta-corrente a um choque com efeito temporário sobre $Z_{t}$

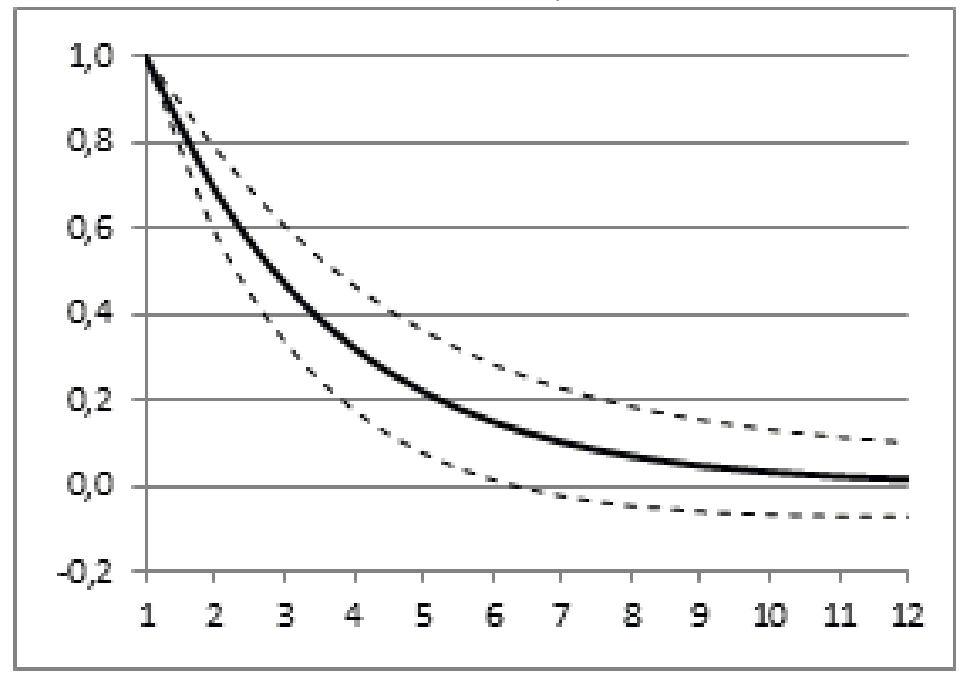

Fonte: Elaboração própria.

Nota: Choques temporários e permanentes na conta-corrente $\left(C A_{t}\right)$ foi obtida empregandose a metodologia proposta por Blanchard e Quah (1989). Os resultados são apresentados normalizados em termos de desvios padrões e os intervalos de confiança para dois desvios padrões foram obtidos a partir de simulação de Monte Carlo com 1.000 repetições. 
Gráfico 7 - Resposta da conta-corrente a um choque com efeito permanente sobre $Z_{\mathrm{t}}$

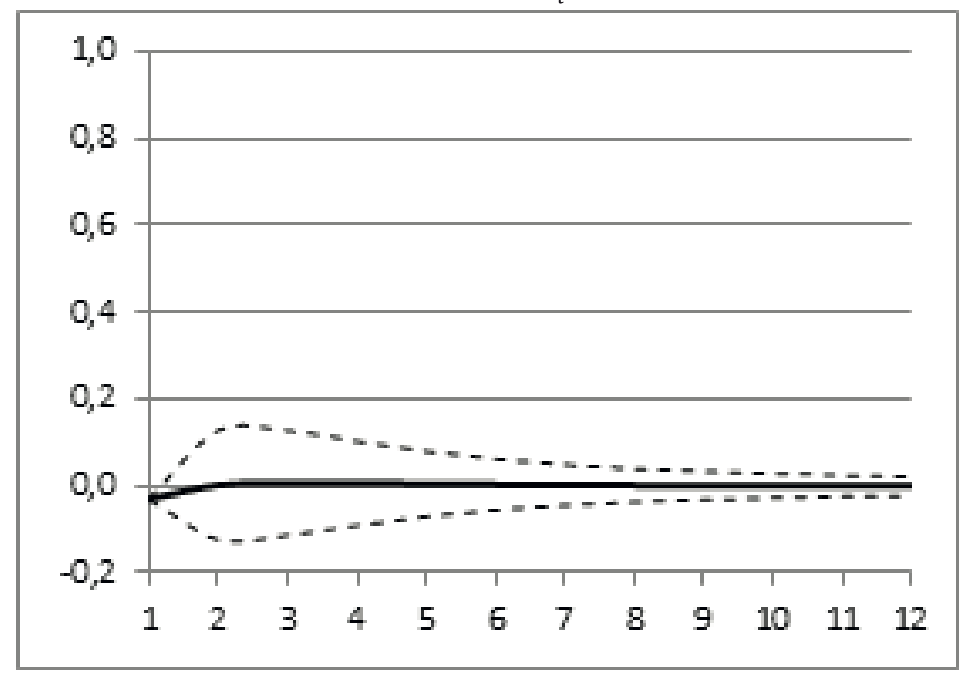

Fonte: Elaboração própria.

Nota: Choques temporários e permanentes na conta-corrente $\left(C A_{t}\right)$ foi obtida empregandose a metodologia proposta por Blanchard e Quah (1989). Os resultados são apresentados normalizados em termos de desvios padrões e os intervalos de confiança para dois desvios padrões foram obtidos a partir de simulação de Monte Carlo com 1.000 repetições.

\section{Discussão dos Resultados}

Nesta seção serão discutidos os resultados das análises realizadas e efetuada sua comparação com os resultados apresentados na literatura. Os resultados deste trabalho mostram que nem todas as proposições básicas testáveis do modelo intertemporal da conta-corrente foram confirmadas, conforme explicado a seguir. Apesar da estacionariedade de conta-corrente em nível ter sido confirmada, não se verificou a causalidade de Granger da conta-corrente para o produto líquido, como o modelo previa. Ao contrário, constatou-se que a conta-corrente não ajuda a prever as variações do produto líquido. Por outro lado, confirmou-se a hipótese de que as séries de conta-corrente ótima e real são estatisticamente iguais. Além disso, verificou-se que a conta-corrente real possui valores absolutos maiores e maior volatilidade do que a conta-corrente ótima e que as duas séries possuem correlação positiva e significativa.

A Tabela 11 mostra os resultados deste trabalho e outros apresentados para a economia brasileira de forma a confirmar a robustez do modelo para alguns resultados quando considerado um período mais recente.

Inicialmente, pode-se observar que a estacionariedade da série para a conta-corrente brasileira é confirmada em todos os trabalhos. Já a hipótese de causalidade no sentido Granger da conta-corrente do Brasil em relação a variações no produto líquido foi confirmada apenas por Ghosh e Ostry (1995). Vale 
ressaltar que Ghosh e Ostry (1995) estudaram as séries de conta-corrente de 45 países em desenvolvimento e empregaram um único procedimento econométrico para todos os casos, além do período analisado para o caso brasileiro ter sido de apenas três décadas, de 1960 a 1990. Todos os trabalhos confirmaram a validade das restrições do VAR, indicando que as séries de conta-corrente ótima e real são estatisticamente iguais para os quatro períodos analisados. Em relação à razão da variância entre as séries estimada e real e à correlação das séries, apenas Silva e Andrade (2006) obtiveram uma série ótima com volatilidade próxima à série real e uma correlação negativa entre as séries. Em relação ao parâmetro $\theta$, todas as estimativas ficaram entre 0.93 e 0.97 , o que reforça a hipótese de que o país consome uma quantidade superior ao seu produto líquido permanente, antecipando o consumo.

Importa ainda ressaltar que o modelo apresentou uma robustez importante em relação às variáveis analisadas, sobretudo quando comparamos os três trabalhos que empregaram dados desde 1947: estacionariedade da conta-corrente, não confirmação da causalidade no sentido Granger de $C A_{t}$ para $\Delta Z_{t}$, validade das restrições do VAR, série real mais volátil que a ótima e parâmetro $\theta$ menor que um.

Especificamente em relação aos resultados deste trabalho, obteve-se uma variância intermediária em relação aos dois trabalhos anteriores e a maior de todas as correlações entre as séries ótima e real. Além disso, verificam-se valores crescentes para o parâmetro $\theta$, o que pode ser uma indicação de que o consumidor representativo vem gradativamente direcionando menos o consumo para o presente e que apenas poderá ser efetivamente confirmado como uma tendência efetiva avaliando-se os valores obtidos em trabalhos futuros.

Em relação à função de resposta ao impulso da conta-corrente obtida para choques com efeitos temporários sobre o produto líquido, o resultado deste trabalho é similar ao obtido por Silva e Andrade (2006), uma vez que em ambos os trabalhos constatou-se que esses choques tiveram impacto positivo sobre a conta-corrente, com posterior desaparecimento dos efeitos do choque na função de resposta ao impulso. Em relação aos choques com efeitos permanentes, diferentemente dos resultados de Silva e Andrade, verificou-se que esses choques não afetaram a conta-corrente, o que está de acordo com o que prevê a teoria. 
Tabela 11 - Resultados obtidos na literatura para a economia brasileira

\begin{tabular}{|c|c|c|c|c|}
\hline Testes & $\begin{array}{c}\text { Ghosh e } \\
\text { Ostry (1995) }\end{array}$ & $\begin{array}{c}\text { Senna e } \\
\text { Issler (2000) }\end{array}$ & $\begin{array}{c}\text { Silva e } \\
\text { Andrade (2006) }\end{array}$ & $\begin{array}{l}\text { Este traba- } \\
\text { lho (2012) }\end{array}$ \\
\hline 1. Período analisado & $1960-1990$ & $1947-1997$ & $1947-2003$ & $1947-2010$ \\
\hline $\begin{array}{l}\text { 2. Estacionariedade da } \\
\text { conta-corrente }\end{array}$ & SIM & SIM & SIM & SIM \\
\hline $\begin{array}{l}\text { 3. Causalidade no sentido } \\
\text { Granger da } C A_{t} \text { para } \Delta Z_{t}\end{array}$ & SIM & NÃO & NÃO & NÃO \\
\hline $\begin{array}{l}\text { 4. Validade das restrições } \\
\text { do VAR }\end{array}$ & SIM & SIM & SIM & SIM \\
\hline $\begin{array}{l}\text { 5. Comparação das séries } \\
\text { (razão das variâncias real/ } \\
\text { ótima e correlação das } \\
\text { séries) }\end{array}$ & $0.15 / \mathrm{ND}$ & $9.36 / 0.52$ & $1.21 /-0.52$ & $4.00 / 0.67$ \\
\hline 6. Parâmetro $\theta$ & 0.97 & 0.93 & 0.95 & 0.96 \\
\hline $\begin{array}{l}\text { 7. Análise da função de } \\
\text { reposta ao impulso da } \\
\text { conta-corrente }\end{array}$ & ND & ND & SIM & SIM \\
\hline
\end{tabular}

Fonte: Elaboração própria.

Nota: ND = não disponível.

\section{Considerações Finais}

O modelo intertemporal da conta-corrente vem sendo aplicado para a economia de alguns países com o objetivo de medir a mobilidade de capitais. $\mathrm{O}$ presente trabalho apresentou a aplicação do modelo para o Brasil para um período que considera as importantes mudanças macroeconômicas no cenário nacional e internacional nos anos mais recentes. Os resultados deste trabalho foram comparados com artigos da literatura que estudaram outros períodos, visando confirmar a robustez de alguns fatos estilizados.

Basicamente, quatro proposições testáveis do modelo foram examinadas:

a) a estacionariedade da série de conta-corrente real do Brasil;

b) a causalidade no sentido de Granger da conta-corrente para as variações do produto líquido;

c) a igualdade entre as duas séries de conta-corrente, ótima e real; e

d) a comparação da volatilidade dessas séries.

Nem todas as implicações do modelo foram verificadas para os dados brasileiros. Apesar da estacionariedade de conta-corrente em nível ter sido confirmada, não se verificou a causalidade de Granger da conta-corrente para o produto líquido, como era previsto pelo modelo. Ao contrário, constatou-se que a contacorrente não ajuda a prever as variações do produto líquido. Por outro lado, confirmou-se a hipótese de que as séries de conta-corrente ótima e real são estatis- 
ticamente iguais e verificou-se que a conta-corrente real possui valores absolutos maiores e maior volatilidade do que a conta-corrente ótima, além das duas séries possuírem correlação positiva e significativa. Devido ao fato de que nem todas as proposições testáveis confirmaram o modelo teórico para o período estudado neste trabalho, conclui-se que o modelo intertemporal da conta-corrente não foi totalmente aceito. Nesse caso, poderia concluir-se que há apenas uma mobilidade parcial de capitais para o período analisado da economia brasileira. Essa rejeição corrobora os resultados obtidos anteriormente nos trabalhos de Senna e Issler (2000) e de Silva e Andrade (2006). Além disso, ainda comparando-se os resultados obtidos com trabalhos anteriores, verificam-se valores crescentes para o componente de tendência do consumo, o que pode ser uma indicação de que o consumidor representativo vem gradativamente direcionando menos o consumo para o presente. Essa avaliação, no entanto, apenas poderá ser efetivamente confirmada como uma tendência efetiva avaliando-se as estimativas obtidas para o parâmetro em trabalhos futuros.

A análise da função de resposta ao impulso da conta-corrente obtida mostrou que choques com efeitos temporários sobre o produto líquido impactaram positivamente a conta-corrente e que choques com efeitos permanentes não afetaram a conta-corrente, conforme havia sido previsto pelo modelo.

\section{Referências}

BLANCHARD, O. J.; QUAH, D. The Dynamic Effects of Aggregate Demand and Supply Disturbances. The American Economic Review, Nashville, US, v. 79, n. 4, p. 655-673, Sept. 1989.

CAMPBELL, J. Y. Does saving anticipate declining labor income? An alternative test of the permanent income hypothesis. Econometrica, Chicago,US, v. 55, n. 6, p. 1249-1273, Sept. 1987.

CAMPBELL, J. Y.; SHILLER, R. J. Cointegration and tests of present value models. Journal of Political Economy, v. 95, n. 5, p. 1062-1088, 1987.

ENDERS, W. Applied econometric time series. 3th ed. New York: Wiley, 2010.

ENGLE, R. F.; GRANGER, C. W. Co-Integration and error correction: Representation, estimation, and testing. Econometrica, Chicago, US, v. 55, n. 2, p. 251-276, Mar. 1987.

GHOSH, A. R. International capital mobility amongst the major industrialized countries: too little or too much? Economic Journal, Cambridge, GB, v. 105, n. 428, p. 107-28, Jan. 1995.

GHOSH, A. R.; OSTRY, J. D. The current account in developing countries: A perspective from the consumption-smoothing approach. World Bank Economic Review, Washington, US, v. 9, n. 2, p. 305-33, 1995.

GRUBER, J.W. A present value test of habits and the current account. Journal of Monetary Economics, Amsterdam, NL, v. 51, n. 7, p. 1495-1507, Oct. 2004. 
NASON, J. M.; ROGERS, J. H. The present-value model of the current account has been rejected: Round up the usual suspects. Journal of International Economics, Amsterdam, NL, v. 68, n. 1, p. 159-187, Jan. 2006.

OBSTFELD, M.; ROGOFF, K. Foundations of international macroeconomics. Cambridge, US: The MIT Press, 1996.

OTTO, G. Testing a present-value model of the current account: evidence from us and Canadian time series. Journal of International Money and Finance, Amsterdam, NL, v. 11, n. 5, p. 414-30, Oct. 1992.

SACHS, J. The current account and macroeconomic adjustment in the 1970's. Brooking Papers on Economic Activity, Washington, v. 1, p. 201-268, 1981.

SENNA, F. A.; ISSLER, J. V. Mobilidade de capitais e movimentos da conta corrente do Brasil: 1947-1997. Estudos Econômicos, Rio de Janeiro, v. 30, n. 4, p. 493-523, abr. 2000.

SHEFFRIN, S. M.; WOO, W. T. Present value tests of an intertemporal model of the current account. Journal of International Economics, Amsterdam, NL, v. 29, n. 3-4, p. 237-253, Nov. 1990.

SHEFFRIN, S. M.; BERGIN, P. R. Interest rates, exchange rates and present value models of the current account. Economic Journal, Cambridge, GB, v. 110, n. 463, p. 535-558, Apr. 2000.

SILVA, N.; ANDRADE, J. P. de. Dinâmica da conta de transações correntes do Brasil: avaliação do modelo básico da abordagem intertemporal. Pesquisa e Planejamento Econômico, Rio de Janeiro, v. 36, n. 3, p. 525-550, dez. 2006.

Abordagem intertemporal da conta corrente: introduzindo câmbio e juros no modelo básico. Economia Aplicada, Ribeirão Preto, v. 11, n. 2, p. 157-187, abr./jun. 2007.

Recebido em: 22/01/2012.

Aceito em: 20/08/2012. 